\title{
EVALUATION OF GINGIVAL TISSUE PATHOLOGICAL CHANGES IN HUMAN PERI-IMPLANTITIS: HISTOLOGICAL, IMMUNOHISTOCHEMICAL AND ULTRASTRUCTURAL STUDY
}

\author{
Elsayed Mohamed Deraz*, Omar Soliman ${ }^{* *}$ and Reda Gaber Saleh ${ }^{* * *}$
}

\begin{abstract}
Aims: The current research was performed to study histopathological, immunohistochemical and ultrastructural characteristics of gingival tissue in peri-implantitis.

Methods \& Results: This study examined 25 patients between ages of 30-40 years. Twenty patients were selected with peri-implantitis (peri-implantitis group) in which inflamed gingival tissues were surgically removed. The gingival soft tissue collars from five healthy patients with partially impacted third molar were surgically removed (control group). All gingival tissue samples were examined histologically and ultrastructurally. Immunoreactivity to CD3 and CD20 antibodies was also evaluated. Cases of peri-implantitis stained with hematoxylin and eosin demonstrated hyperplastic nonkeratinized epithelium with downward growth of rete ridges. Connective tissue stroma revealed prominent vascularity, proliferation of fibrous tissue and focally aggregated inflammatory cell infiltration localized to the subepithelial area. Immunohistochemical results exhibited large numbers of $\mathrm{T}(\mathrm{CD} 3+)$ and $\mathrm{B}(\mathrm{CD} 20+)$ lymphocytes in peri-implantitis compared to normal tissue with a statistically significant difference. All cases of peri-implantitis demonstrated no significant difference between $\mathrm{T}$ and B lymphocytes. Transmission electron microscope showed wide intercellular spaces with fine bundles of keratin intermediate filaments around the nucleus. Fibrous connective tissue stroma with active fibroblasts and numerous mixed inflammatory cells (plasma cells, mast cells and numerous activated lymphocytes) were also revealed.
\end{abstract}

Conclusions: Variable histopathological changes appeared in peri-implantitis soft tissue including hyperplastic nonkeratinized epithelium, mixed inflammatory cell infiltration with no statistical difference between $\mathrm{T}$ and $\mathrm{B}$ lymphocytes, excessive collagenization and vascular proliferation. Understanding these histopathological alterations may help clinicians in better management of peri- implantitis condition to ensure longevity of dental implants.

KEYWORDS: CD3 and CD20 antibodies, gingiva, histological, human, immunohistochemical, peri-implantitis, $\mathrm{T}$ and $\mathrm{B}$ lymphocytes, ultrastructural

\footnotetext{
* Assistant Professor of Oral Pathology, Faculty of Dentistry, Tanta University, Egypt.

** Lecturer of Periodontology and Oral Medicine, Faculty of Dentistry, South Valley University.

*** Assistant Professor of Oral Biology, Faculty of Dentistry, Tanta University, Egypt
} 


\section{INTRODUCTION}

Inflammatory lesions affecting the mucosa and supporting bone surrounding an implant are known as peri-implantitis which becoming an increasing and recognized problem in the field of implant dentistry ${ }^{(1)}$. The inflammation that is restricted to the mucosa around the implant without any bony involvement is defined as peri-implant mucositis ${ }^{(2)}$.

Peri-implantitis is diagnosed by detecting bleeding on probing as well as loss of supporting structures ${ }^{(3)}$. It was demonstrated that absence of periodontal ligament or the lateral spread of infection on the surface of implant may influence the morphological and histological characteristics of the lesion ${ }^{(4)}$.

Many common features exist regarding the radiological and clinical signs of peri-implantitis and periodontitis ${ }^{(5)}$. On the other hand, previous experimental results on dogs exhibited significant histopathological changes between these two lesions, in which peri-implantitis sites revealed inflammatory cell infiltrates that were larger and contained larger proportions of neutrophils and osteoclasts than in periodontitis. ${ }^{(6)}$.

Histopathological and ultrastructural alterations in gingival tissue in periodontitis have been extensively studied at experimental and human levels ${ }^{(6-8)}$. Previously, inflammatory cell infiltrate chiefly lymphocytes were elicited in the subjacent connective tissue in soft tissues surrounding implants in peri-implantitis ${ }^{(6)}$. In the literature, however, little is known about $\mathrm{T}$ and $\mathrm{B}$ lymphocytic infiltrate as well as ultrastructural pathological changes in gingival mucosa in peri-implantitis lesions obtained from humans. Therefore, the current study was performed to evaluate the characteristics of gingival tissue in human peri-implantitis condition at histological, immunohistochemical and ultrastructural levels.

\section{MATERIALS AND METHODS}

\section{Participants}

Twenty-five individuals between ages of 30-40 years were examined in this study, these patients must have meet specific inclusion criteria to participate in this study. All participants were screened during periodontal consultations in the Department of Periodontology and Oral Medicine, Faculty of Dentistry, South Valley University, Egypt. We informed them about peri-implantitis and the objectives of the study and provided them with a complete protocol. All participants signed an informed consent agreement. The patients were divided into two groups. Twenty patients selected with periimplantitis (peri-implantitis group), the range of the loading time of the implants in selected patients was 1-2 years. The duration of the inflammation ranged from 1-3 months. Five healthy patients with impacted third molar (control group) with no evidence of inflammation. The study protocol was approved by the Research Ethics Committee of Faculty of Dentistry, Tanta University, Egypt.

\section{Inclusion and exclusion criteria of peri-implantitis}

Inclusion criteria for participants involve signs of peri-implantitis with bleeding on probing (with/ without suppuration); peri-implant probing pocket depth $>5 \mathrm{~mm}$; radiographic evidence of bone loss 2 $\mathrm{mm}$. The exclusion criteria were as follows: smoker individuals; occlusal overload implants (checked by occlusion papers); periodontitis; systemic disease or treatment, such as bisphosphonates, diabetes type 1 , or inflammatory diseases that might influence treatment or outcome; pregnancy; presurgical antibiotic (local or systemic) or oral antiseptic for three months; high dosage corticosteroids therapy; and radiotherapy of the head and neck district (Figure 1.A).

\section{Radiographic Examination}

Intra-oral radiographs were collected for each implant using the long cone paralleling technique 


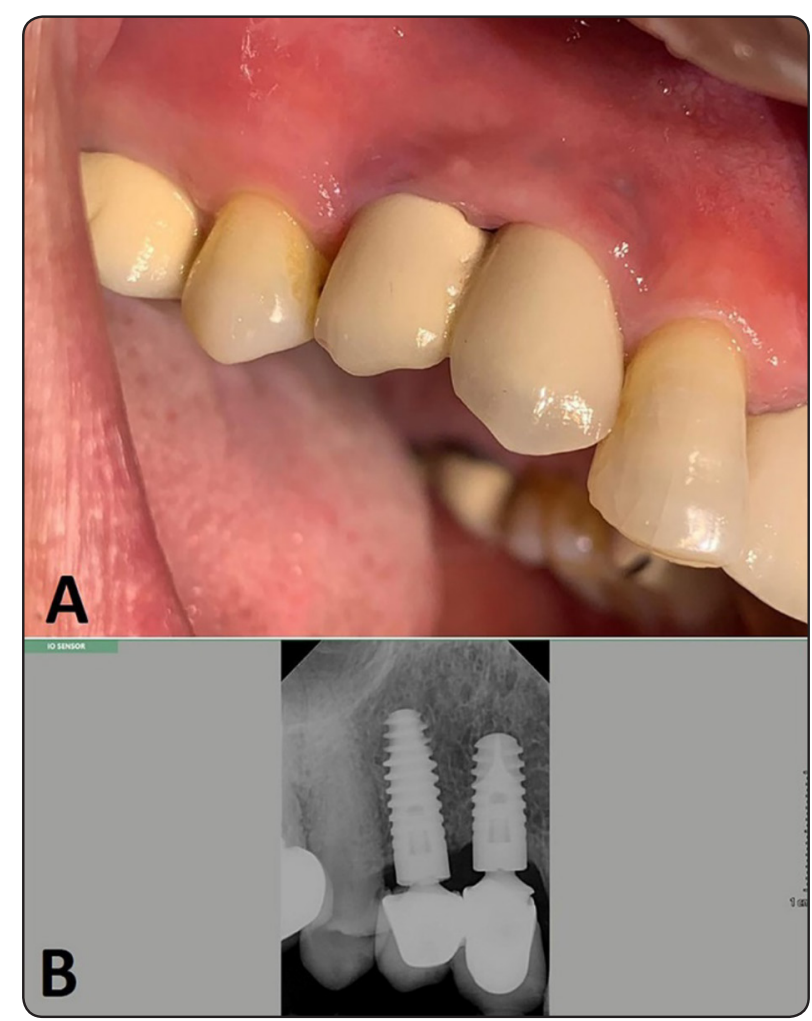

Fig. (1) (A) A case of peri implantitis exhibits swelling of the peri-implant soft tissue. (B) Radiographical image of the same patient shows resorption of bone around the implant (arrows).

with periapical $\mathrm{x}$ ray. We used the implant-crown interface as the reference level and measured the distance $(\mathrm{mm})$ between it and the bone surface for each implant (Figure 1.B).

\section{Surgical procedure}

Surgical procedures were performed under local anesthesia. In control group, free gingival soft tissue collars were removed from partially impacted third molar teeth after extraction at the Department of Oral and Maxillofacial Surgery, Faculty of Oral and Dental Medicine, South Valley University, Egypt. In peri-implantitis group, peri-implant inflamed gingival tissues were dissected using a scalpel during the scaling and root planning procedure or mechanical debridement at the Department of Periodontology and Oral Medicine, Faculty of Dentistry, South Valley
University, Egypt. All gingival tissue samples were examined at histological, immunohistochemical and ultrastructural levels.

\section{Tissue preparation}

The Specimens of excised gingival tissues of peri-implantitis group (GP1) and control group (GP2) were fixed in $10 \%$ buffered formalin for $24 \mathrm{~h}$. Then, they were washed in tap water over night followed by dehydration through ascending graded series of ethanol, cleared in xylene and then embedded in low melting point $\left(56^{\circ} \mathrm{C}\right)$ paraffin. Serial sections of 5 um thickness were processed for histological staining with Harris' haematoxylin and eosin $(\mathrm{H} \& \mathrm{E})^{(9)}$, and for immunohistochemical labeling ${ }^{(10)}$.

\section{Immunohistochemical staining}

Serial sections of 5 um thickness were cut and mounted on commercially available positively charged glass slides. Tissue sections were deparaffinized in xylene, rehydrated in descending grades of ethanol. Endogenous peroxidase activity was blocked with methanol containing $0.3 \% \mathrm{H} 2 \mathrm{O} 2$ for 30 minutes. Antigen retrieval was done by microwaving using citrate phosphate buffer ( $\mathrm{pH}$ 6.0), then the sections were incubated with the primary antibodies at $4^{\circ} \mathrm{C}$ overnight. Immunohistochemical staining was carried out by a rabbit polyclonal Anti-CD3 antibody to detect T lymphocytes (1:100 dilution; Abcam, Cambridge Biomedical Campus, Cambridge, UK) and mouse monoclonal AntiCD20 antibody to highlight B lymphocytes (1:100 dilution; clone L26, Abcam, Cambridge Biomedical Campus, Cambridge, UK). For detection of the reaction after incubation with secondary antibodies, we used diaminobenzidine (1:100 dilution; Abcam, Cambridge Biomedical Campus, Cambridge, UK). The hematoxylin was used to counterstain the sections, ascending grades of ethanol were used to dehydrate the slides and finally they were mounted. In negative controls, the pre-immune serum was used to replace the primary antibody. 


\section{Transmission electron microscopic examination}

Gingival samples were sliced into small pieces and fixed in a combination of $1.25 \%$ glutaraldehyde and $1 \%$ paraformaldehyde in $0.1 \mathrm{M}$ cacodylate buffer ( $\mathrm{pH}$ 7.2) for 2 hours. Then, cacodylate buffer accompanying with $3.5 \%$ sucrose were used to rinse the samples, followed by fixation with osmium tetroxide, dehydration, and embedding in Epoxy Resin. Semithin sections were examined after toluidine blue staining. Diamond knife was used to cut ultrathin sections (90- $100 \mathrm{~nm}$ ), which collected on grids, stained with (uranyl acetate and bismuth subnitrate), and finally examined and photographed in a JEOL 100S (Tanta University, Faculty of Medicine, Egypt).

\section{Statistical evaluation}

After processing and staining, the slides are visualized in Leica DM500 light microscope with built-in camera system (Leica ICC50 HD). Images of the immunostained sections were analyzed by the ImageJ analysis system (ImageJ 1.48s, Wayne Rasband, National Institute of Health, USA). Only cells showing round-shaped appearance were selected to ensure that these cells are inflammatory and to exclude fibroblasts.

Images for inflammatory cell counting in immunohistochemical reaction of CD3 and CD20 antibodies-were acquired from areas expressed the immunohistochemical DAB brown color reaction. Sections were analyzed by counting of antibodies expression. Each type of cells was counted in five fields of (X 400 magnification.

The paired and independent t-test were used for the statistical analyses according to Mould, 1989 (11). All values were expressed in form of means and standard deviations. The statistical analyses were done on an IBM PC using the statistical software "SPSS 20" (Statistical Package for Scientific
Studies) (SPSS Inc., Chicago, Illinois, USA) for windows. Results were expressed in the form probability value ( $p$-value) that was differentiated into: non-significant when $\mathrm{p}$-value $>0.05$, significant when $p$-value $\leq 0.05$, highly significant when $p$-value $\leq 0.01$.

\section{RESULTS}

\section{Histological results}

H\&E-stained tissue sections of control group revealed normal gingiva, which was covered by normal thickness of parakeratinized stratified squamous epithelium with delicate underlying connective tissue. The latter showed fine collagen fibrils and small normal sized blood capillaries with no inflammatory cell infiltration (Figure 2). On the other hand, the gingival tissue in peri-implantitis group demonstrated hyperplastic nonkeratinized stratified squamous epithelium with elongation and downward growth of rete ridges. The underlying connective tissue revealed condensed thick collagen fibers with inflammatory cell infiltration in addition to delicate congested thick-walled blood vessels (Figure 3)

\section{Immunohistochemical results}

In normal gingiva, CD3 Immunostaining was detected in the cytoplasm and the cell membrane of $\mathrm{T}$ lymphocytes. These positive cells were shown to be sporadic and restricted to the subepithelial CT as well as basal and parabasal epithelial layers. In case of peri-implantitis specimens, the CD3 immunoexpression was revealed in sporadic cells of basal and parabasal epithelial layers. However, intense CD3 expression was exhibited in subepithelial connective tissue (Figure 4). On the other hand, no immunohistochemical expression of CD20 was detected in normal gingiva. Intense CD20 immunoreactivity was detected in subepithelial connective tissue (Figure 5) 


\section{Ultrastructural results}

Ultrastructural analysis of normal gingival tissue showed tightly packed keratinocytes connected by desmosomes with narrow intercellular spaces. The keratin intermediate filaments appeared as prominent bundles around the nucleus. Normal connective tissue stroma was noticed with normal fibroblast and inactive lymphocytes (Figure 6). In peri-implantitis specimens, epithelial cells showed a prominent prickly appearance with wide intercellular spaces. The keratin intermediate filaments appeared as fine bundles around the nucleus. Connective tissue stroma revealed large active fibroblasts tightly surrounded by longitudinal and transverse sections of collagen fibers. In addition to, numerous types of inflammatory cells were appeared such as plasma cells, mast cells and numerous lymphocytes imbedded in fibrotic stroma. Activated lymphocytes showed mutable microvilli, proliferated rough endoplasmic reticulum (RER), membrane bound bodies with hybrid content and a few electron lucent vesicles was noted in the cytoplasm (Figure 7).

\section{Statistical results}

The inflammatory cell counting of $\mathbf{T}$ and $B$ lymphocytes: The greatest mean counting values of CD3 and CD20 positive cells were recorded in peri-implantitis group with the least value obtained in control group. The independent t-test revealed highly significant difference between the two groups (p-value $<0.000$ ) (Table 1, Figure 8). The paired t-test between CD3 and CD20 positive cells showed no significant difference between the numbers of $\mathrm{T}$ and $\mathrm{B}$ lymphocytes in peri-implantitis group (Table 2).

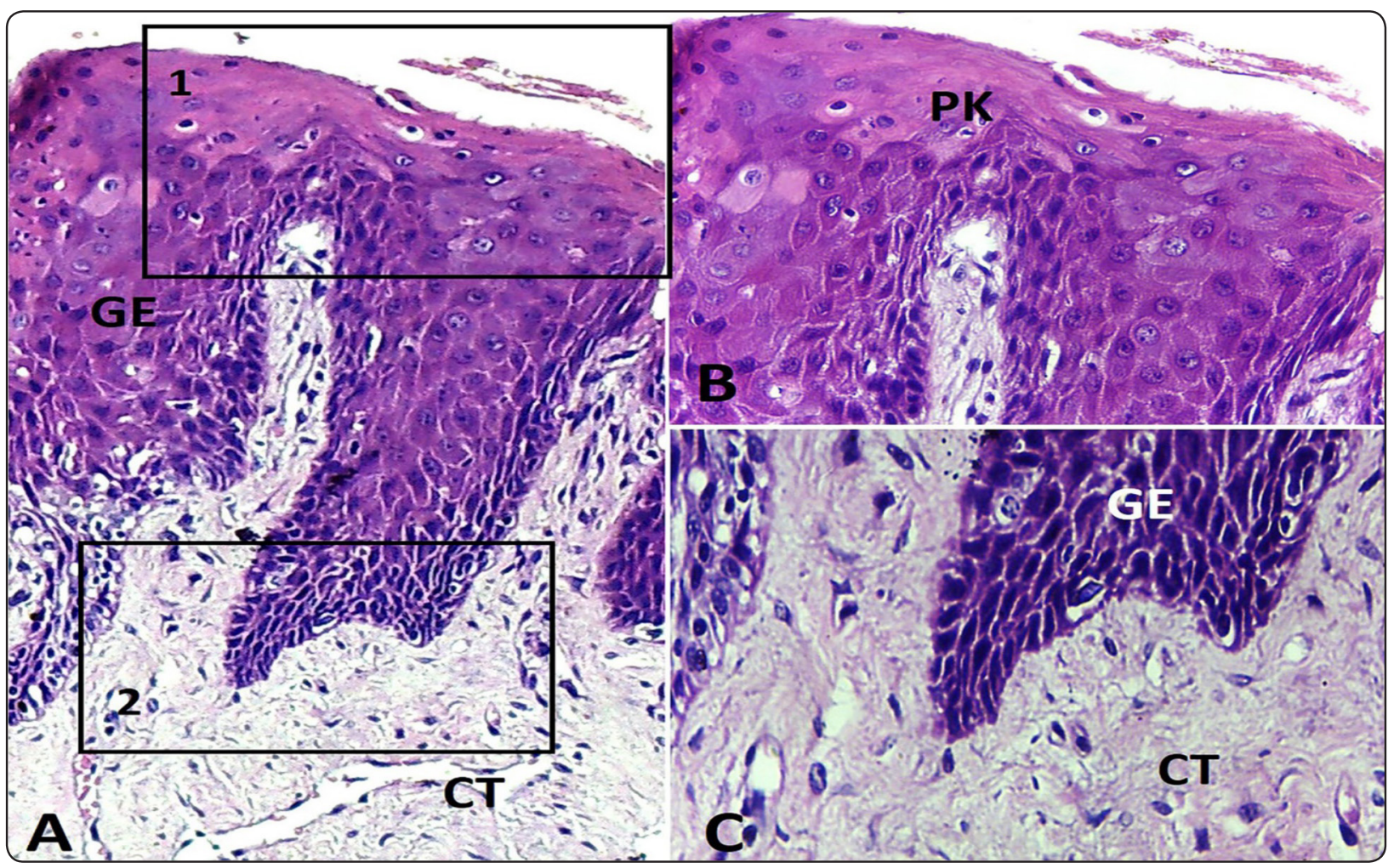

Fig. (2) Light micrograph of normal human gingiva. (A) Low power of normal gingiva epithelium and CT, with long slender epithelial ridges. (B) Higher magnification (frame 1) of figure (A) parakeratinized stratified squamous epithelium (PK). (C) Higher magnification (frame 2) of figure (A) delicate underlying CT. (GE) gingiva epithelium, (CT) connective tissue. (H and $\mathrm{E}$ original magnification, $\mathrm{A} \times 10, \mathrm{~B} \& \mathrm{C} \times 40$ ). 


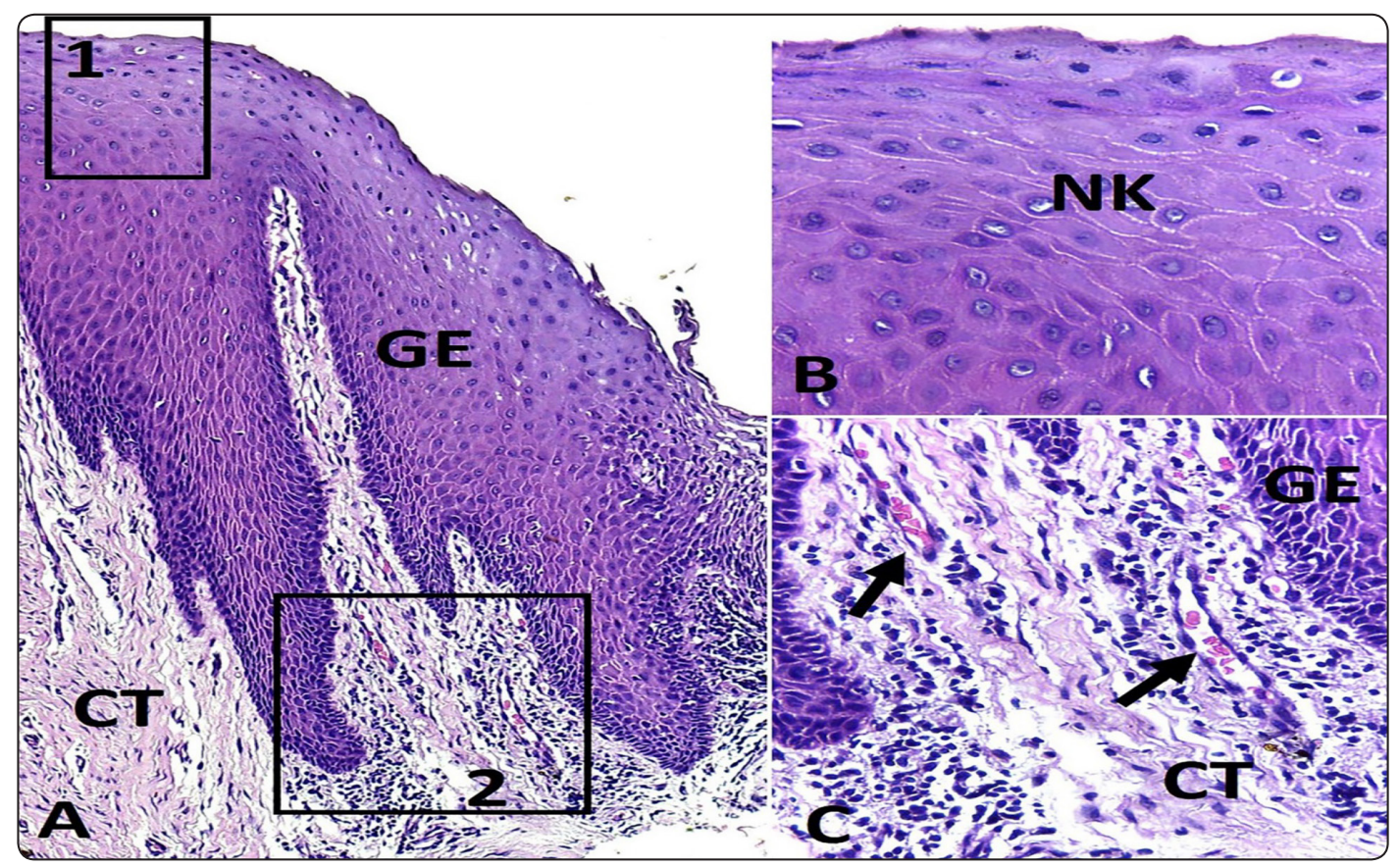

Fig. (3) Light micrograph of peri-implantitis human gingiva. (A) Low power of hyperplastic gingiva epithelium with downward growth of epithelial ridges, inflamed CT. (B) Higher magnification (frame 1) of figure (A) nonkeratinized stratified squamous epithelium (NK). (C) Higher magnification (frame 2) of figure (A) dense thick fibered CT with inflammatory cell infiltration, congested thick-walled blood vessels (arrow). (GE) gingiva epithelium, (CT) connective tissue. (H and E original magnification, $\mathrm{A} \times 10, \mathrm{~B} \& \mathrm{C} \times 40)$.

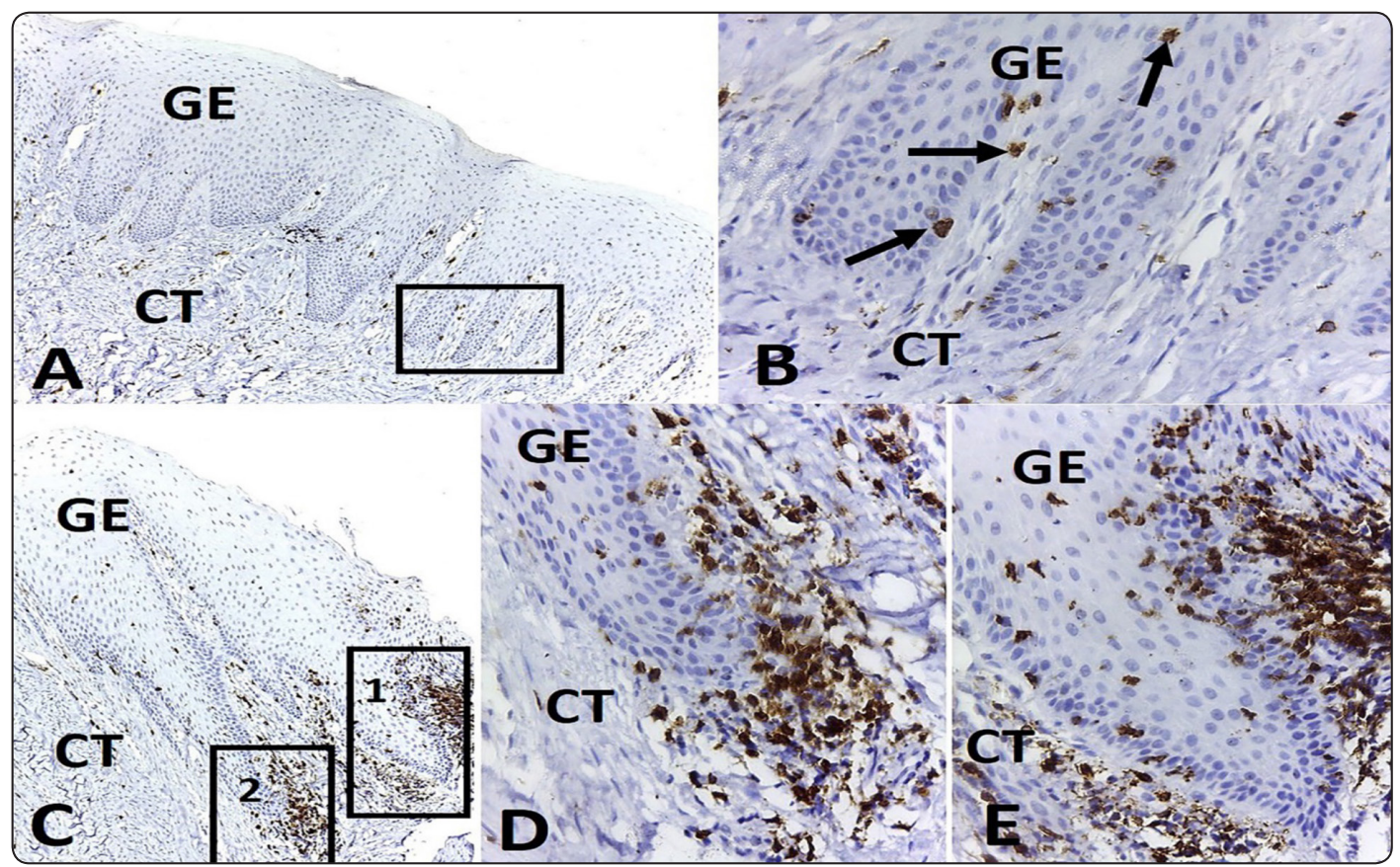

Fig. (4) Immunohistochemical staining of Anti-CD3 antibody in human gingiva. (A) Low power of normal gingiva with few CD3 expression. (B) Higher magnification of figure (A) restriction of CD3 expression in basal and parabasal epithelial layers as well as subepithelial CT (arrow). (C) Low power of peri-implantitis gingiva with intense CD3 expression in subepithelial CT. (D\&E) Higher magnification (frame $1 \& 2$ respectively) of figure (C) sporadic CD3 cytoplasmic expression of basal and parabasal epithelial layers, with intense expression in subepithelial CT. (GE) gingiva epithelium, (CT) connective tissue. (Original magnification, $\mathrm{A} \& \mathrm{C} \times 4, \mathrm{~B}, \mathrm{D} \& \mathrm{E} \times 40$ ). 


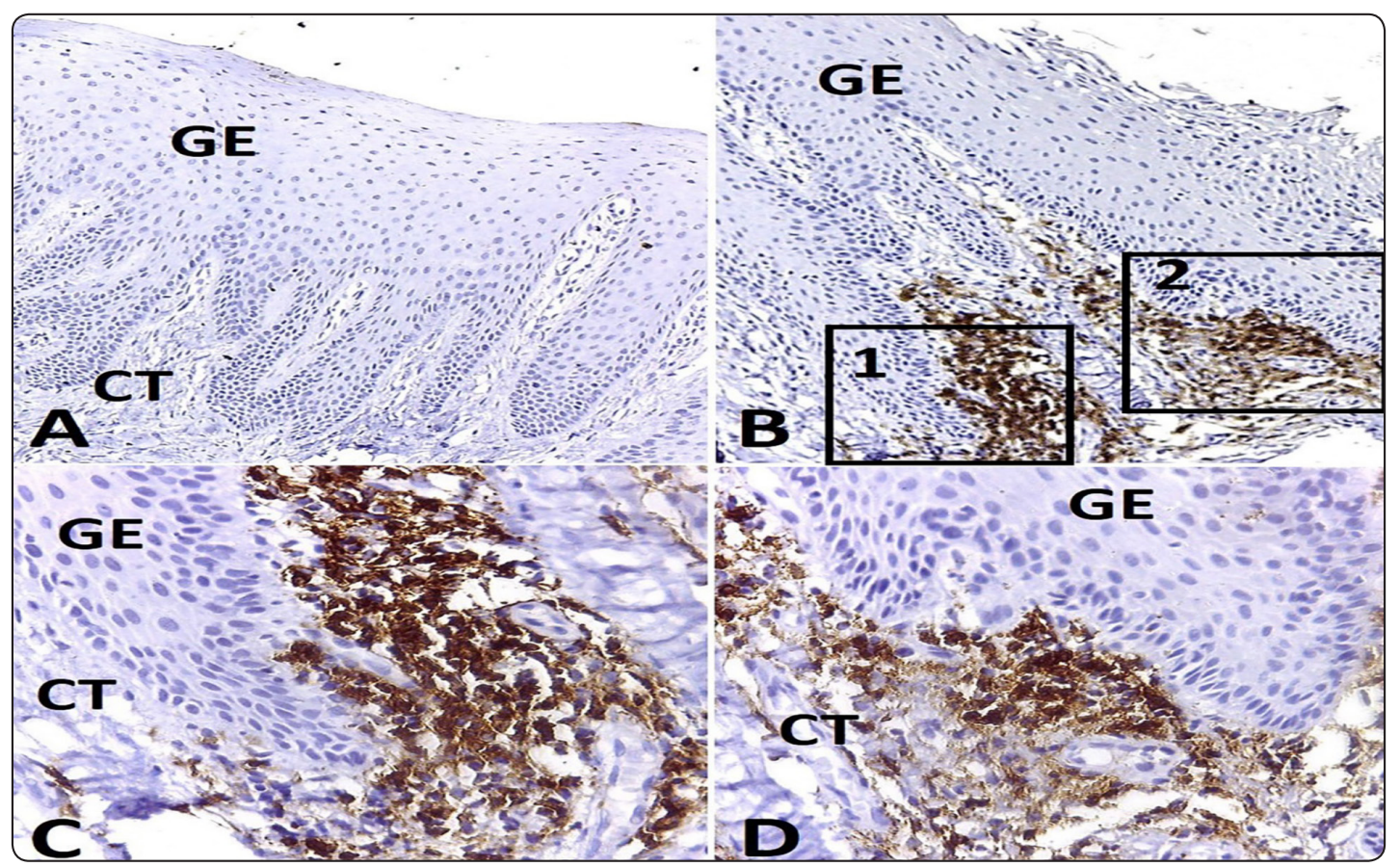

Figure 5. Immunohistochemical staining of Anti-CD20 antibody in human gingiva. (A) Low power of normal gingiva with no CD20 expression. (B) Low power of peri-implantitis gingiva with subepithelial CT (arrow). (C\&D) Its higher magnifications (frame $1 \& 2$ respectively of figure B) showing intense CD20 expression in subepithelial CT. (GE) gingiva epithelium, (CT) connective tissue. (Original magnification, $\mathrm{A} \& \mathrm{~B} \times 10, \mathrm{C} \& \mathrm{D} \times 40$ ).

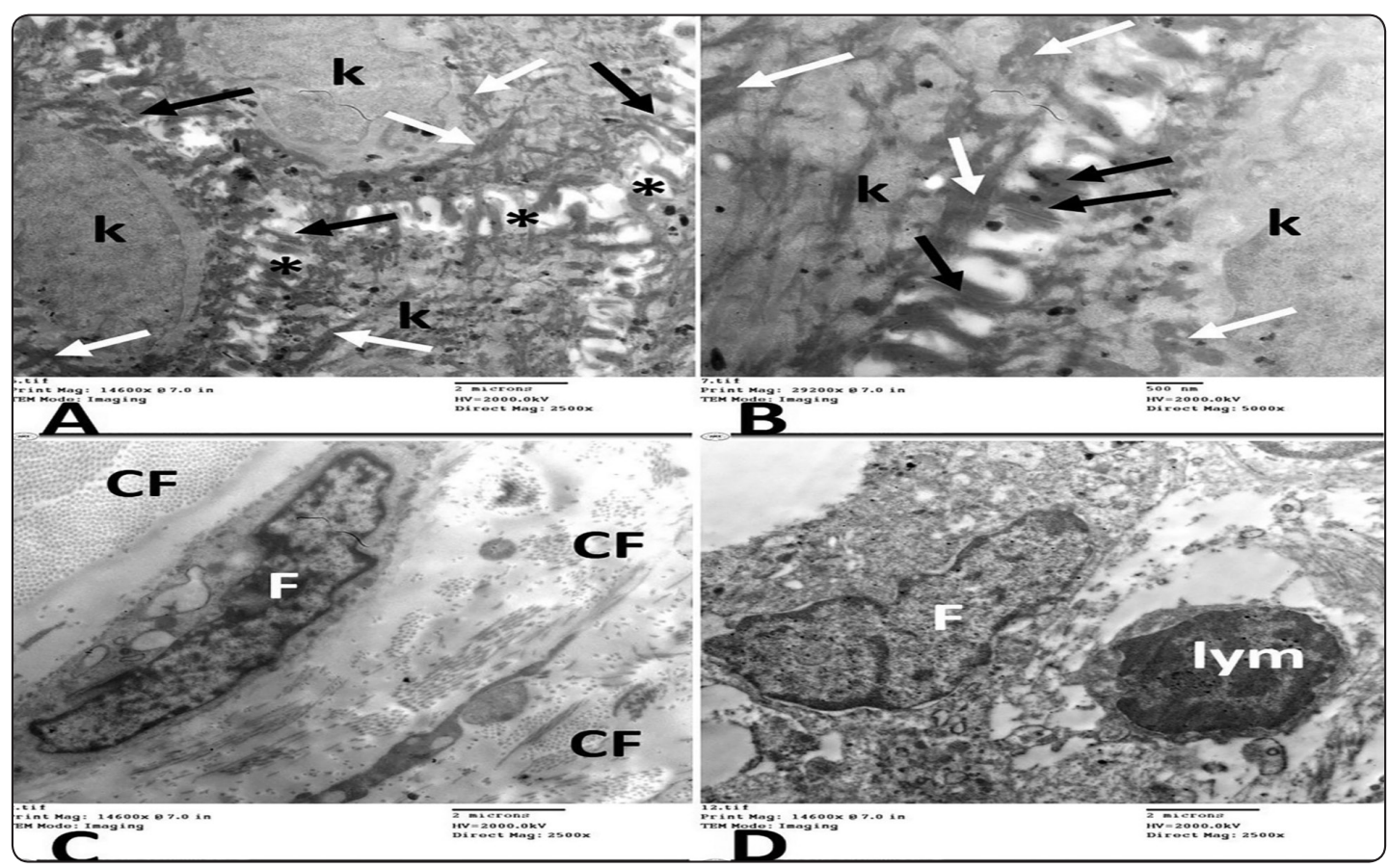

Fig. (6) Transmission electron microscopy (TEM) analyses of normal human gingiva. (A\&B) keratinocytes with desmosomal junction (black arrows), bundles of keratin intermediate filaments (white arrows), and narrow intercellular spaces (*). (C) In active fibroblasts (F) with small amount of LS \& TS of CF. (D) CT stoma with fibroblasts (F) and small in active lymphocytes (lym). (LS \& TS) longitudinal and transverse sections, (CF) collagen fibers, (CT) connective tissue, (k) keratinocyte. 


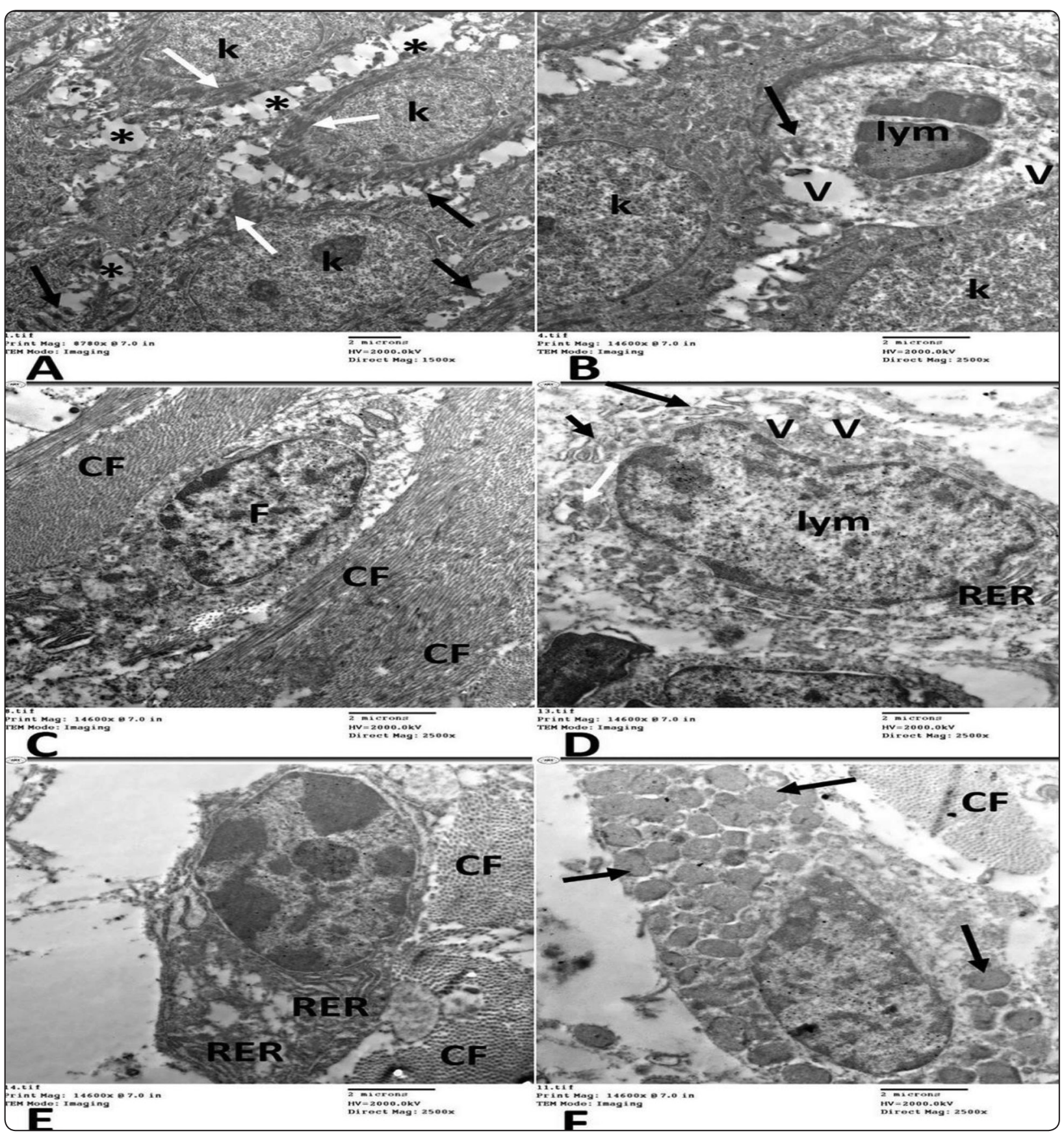

Fig. (7) Transmission electron microscopy (TEM) analyses of peri-implantitis soft tissue. (A) keratinocytes with desmosomal junction (black arrows), prominent bundles of keratin intermediate filaments (white arrows), and wide intercellular spaces (*). (B) intraepithelial lymphocytes (lym) with heterochromatin clumping adjacent to the nuclear membrane, membrane bound bodies (black arrow), a few electron lucent vesicles (V). (C) active fibroblasts (F) with LS \& TS of CF. (D) Stromal activated lymphocytes showed mutable microvilli (black arrows), proliferated RER, membrane bound bodies with hybrid content are noted in the cytoplasm (white arrow), a number of electron lucent vesicles (V) are also seen. (E\&F) fibrotic stoma with inflammatory cells infiltration, plasma cells with prominent RER (in fig. E) and mast cells filled with membrane pounded granules (black arrows) (in fig. F). (LS \& TS) longitudinal and transverse sections, (CF) collagen fibers, (k) keratinocyte 
TABLE (1) Independent t-test of the means of T and B lymphocytes counting in control and peri-implantitis group.

\begin{tabular}{|c|c|c|c|}
\hline & $\begin{array}{c}\text { control group } \\
(\mathrm{n}=5)\end{array}$ & $\begin{array}{c}\text { peri-implantitis group } \\
(\mathrm{n}=20)\end{array}$ & P-value \\
\hline CD3 antibody + T lymphocytes (mean \pm SD) & $255 \pm 14.64$ & $794 \pm 74.02$ & $0.000^{* *}$ \\
\hline CD20 antibody + B lymphocytes (mean \pm SD) & $0 \pm 0.00$ & $830 \pm 90.26$ & $0.000^{* *}$ \\
\hline
\end{tabular}

** Highly significant; $S D$, standard deviation

TABLE (2) Paired t-test of the means of T and B lymphocytes counting in peri-implantitis group.

\begin{tabular}{|l|c|c|c|}
\hline & $\begin{array}{c}\text { CD3 antibody + T lymphocytes } \\
(\mathrm{n}=20)\end{array}$ & $\begin{array}{c}\text { CD20 antibody + B lymphocytes } \\
(\mathrm{n}=20)\end{array}$ & P-value \\
\hline peri-implantitis group $($ mean \pm SD) & $794 \pm 74.02$ & $830 \pm 90.26$ & $0.16^{*}$ \\
\hline
\end{tabular}

* non-significant when p-value $>0.05$; $S D$, standard deviation

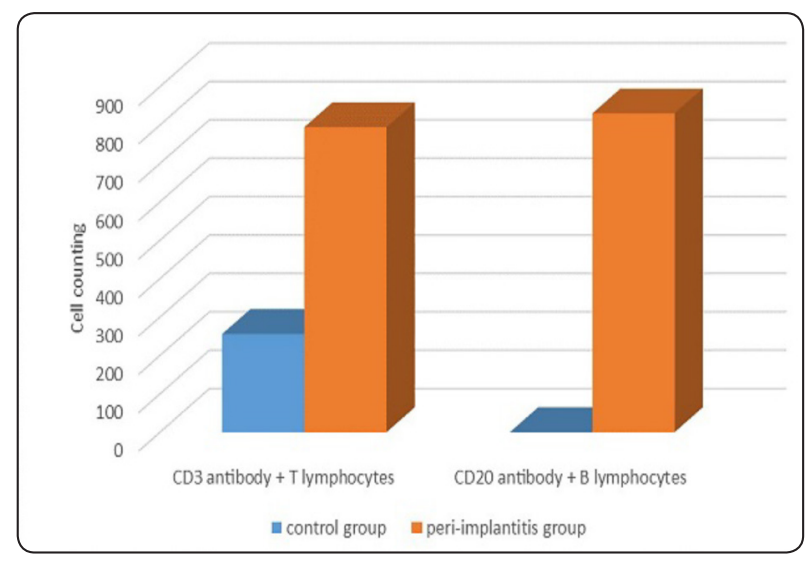

Fig. (8) Column charts representing the mean values of $\mathrm{T}$ and B lymphocytes counting in control and peri-implantitis group.

\section{DISCUSSION}

Compromising the quality and quantity of the soft and hard tissues surrounding an implant are important and recognizing complications that occur in implant therapy and include inflammation of soft tissues, resorption of bone and eventually the loss of the implant itself ${ }^{(12)}$.

The current work evaluated histopathological characteristics of peri-implant soft tissue in human peri-implantitis. In contrast to normal tissue and according to our histological, immunohistochemical and ultrastructural results, cases of peri-implantitis demonstrated prominent vascularity and mixed inflammatory cell infiltrate. There were large numbers of $\mathrm{T}$ and $\mathrm{B}$ lymphocytic cells in periimplantitis compared to normal tissue with a statistically significant difference. All cases of peri-implantitis demonstrated no significant difference between numbers of $\mathrm{T}$ and $\mathrm{B}$ cells. Both lymphocytes were focally aggregated and localized to the subepithelial area. Moreover, proliferation of fibrous tissue bundles was also noted in subepithelial connective tissue.

In accordance with our objectives, Pais and Slavescu ${ }^{(13)}$ demonstrated early failure of two dental implants in human which emphasized the need for microscopic evaluation of failed implants to illustrate and explain the variable histopathological findings in these cases. From an ethical point of view, biopsies are restricted to the gingival soft tissue component that surrounds the implants as the supporting bone is not accessible for sampling. In contradistinction, biopsies derived from animal experiments in peri-implantitis conditions include both periodontal hard and soft tissue components ${ }^{(6)}$.

Our present results are consistent with those of Mijiritsky et al ${ }^{(14)}$ who reported an inflammatory infiltrate underneath the epithelium with collagen fibers in peri-implantitis tissue as well as a differ- 
ent distribution of blood vessels throughout the connective tissue. In contrast to our findings, some other studies have demonstrated an inflammatory infiltrate that was of T-cell dominated one in both normal gingival and peri-implantitis tissues ${ }^{(15,16)}$. In addition, the reactions of gingival peri-implant mucosa to plaque accumulation in human were studied by Zitzman et al ${ }^{(17)}$ who reported an increase in both $\mathrm{T}$ and $\mathrm{B}$ lymphocytes with predominance of $\mathrm{T}$ lymphocytes. Furthermore, analysis of soft tissue biopsies from five cases of peri-implantitis indicated the presence of mixed inflammatory cell infiltrate consisting of plasma cells, macrophages and lymphocytes and that $\mathrm{T}$ lymphocytes were more common than $\mathrm{B}$ cells ${ }^{(7)}$.

It has been demonstrated that $\mathrm{T}$ lymphocytes have an immunoregulatory effect and that local immune regulation is dependent on $\mathrm{T}$ cell regulation of $\mathrm{B}$ cell response and that tissue inflammation is proportionally related to the increased level of different inflammatory mediators (18,19). Proinflammatory cytokines have been shown to be expressed in the peri-implant tissue in early stages of inflammation and the values of interleukins (IL) have increased as the peri-implantitis progresses ${ }^{(20)}$. The inflammatory process seen in peri-implantitis condition could be attributed to the exposure to different clinical factors as smoking, poor oral hygiene and plaque accumulation (7). However, more studies have to be conducted to verify these etiological factors and underline other local and systemic causative agents of such cases.

Previous reports have shown that vascular endothelial growth factor (VEGF) may be an important factor in the initiation and progression of gingivitis to periodontitis which in turn expand the vascular network and be compatible with progression of inflammatory process ${ }^{(21,22)}$. Positive cells for VEGF and CD34 in blood vessels were demonstrated in normal peri-implant mucosa ${ }^{(23)}$. In addition, Comelini et al ${ }^{(24)}$ who worked on biopsies from ten patients suffering from peri-implantitis have demonstrated stromal cell positivity for VEGF that was higher in peri-implantitis compared to healthy sites. Similar results have also revealed in another study in which enhanced density of blood vessels were observed in the connective tissue in peri-implantitis ${ }^{(25)}$.

It should also be noted that excessive collagenization was detected in the connective tissue in all cases of peri-implantitis as demonstrated by transmission electron microscope. Our results are in agreement with Mijiritsky et al ${ }^{(14)}$ who demonstrated bundles of collagen fibers in the connective tissue underneath the epithelium in cases of periimplantitis. This finding could be mediated by cytokine pathway that is initiated by particles of implant material and then resulted in collagen production (26). The findings of Curtis et al ${ }^{(27)}$ confirmed the presence of a significantly lower levels of proinflammatory cytokines in healthy tissues surrounding implants compared to peri-implantitis.

In conclusion, our present study provides important insights on the variable histopathological changes occurring in the soft tissue surrounding an implant in peri-implantitis condition including mixed inflammatory cell infiltration with lymphocytic predominance, excessive collagenization and vascular proliferation. Understanding these histopathological alterations in peri-implant tissues can help clinicians in better management of this condition. However, long term studies in human involving a sufficient number of patients are highly recommended to elucidate the exact pathogenic mechanisms underlying these histopathological alterations in peri-implantitis to ensure longevity of dental implants.

\section{REFERENCES}

1. Mombelli A, Müller N, Cionca NJCoir. The epidemiology of peri-implantitis. Clin Oral Implants Res. 2012;23:67-76.

2. Lindhe J, Meyle J, Group DoEWoP. Peri-implant diseases: Consensus Report of the Sixth European Workshop on Periodontology. J Clin Periodontol. 2008;35 (8 Suppl): 282-5. 
3. Lang NP, Berglundh T, periodontology WGotSEWoPJJoc. Periimplant diseases: where are we now?-Consensus of the Seventh European Workshop on Periodontology. Journal of clinical periodontology. 2011;38:178-81.

4. Mombelli A, Decaillet F. The characteristics of biofilms in peri-implant disease. J Clin Periodontol. 2011;38 Suppl 11:203-13.

5. Berglundh T, Zitzmann NU, Donati M. Are periimplantitis lesions different from periodontitis lesions? J Clin Periodontol. 2011;38 Suppl 11:188-202.

6. Carcuac O, Abrahamsson I, Albouy JP, Linder E, Larsson L, Berglundh T. Experimental periodontitis and periimplantitis in dogs. Clin Oral Implants Res. 2013;24 (4):363-71.

7. Bullon P, Fioroni M, Goteri G, Rubini C, Battino M. Immunohistochemical analysis of soft tissues in implants with healthy and peri-implantitis condition, and aggressive periodontitis. Clin Oral Implants Res. 2004;15 (5):553-9.

8. Liljenberg B, Lindhe J, Berglundh T, Dahlen G, Jonsson RJJocp. Some microbiological, histopathological and immunohistochemical characteristics of progressive periodontal disease. Journal of clinical periodontology. 1994;21 (10):720-7.

9. Bancroft JD, Gamble M. Theory and practice of histological techniques. 8th ed: Elsevier health sciences; 2008. 126-38 p.

10. Saleh RG, Deraz EM, Mohammed AARJEDJ. A comparative study of the clinical andhistopathological features of normal labial mucosa and redundant tissue in double lip. Egyptian Dental Journal. 2020;66 (1):165-73.

11. Mould RF. Introductory medical statistics. 3rd ed: CRC Press; 1998. 126-40 p.

12. Galárraga-Vinueza ME, Tangl S, Bianchini M, Magini R, Obreja K, Gruber R, et al. Histological characteristics of advanced peri-implantitis bone defects in humans. International Journal of Implant Dentistry. 2020;6 (1):1-8.

13. Pais ES, Slavescu D. Degenerative and regenerative morphological aspects in peri-implantitis. Ultrastruct Pathol. 2016;40 (4):171-5.

14. Mijiritsky E, Ferroni L, Gardin C, Peleg O, Gultekin A, Saglanmak A, et al. Presence of ROS in Inflammatory Environment of Peri-Implantitis Tissue: In Vitro and In Vivo Human Evidence. J Journal of Clinical Medicine. 2020;9 (1):38.
15. Liljenberg B, Gualini F, Berglundh T, Tonetti M, Lindhe $\mathrm{J}$. Composition of plaque-associated lesions in the gingiva and the peri-implant mucosa in partially edentulous subjects. J Clin Periodontol. 1997;24 (2):119-23.

16. Tonetti MS, Imboden M, Gerber L, Lang NP. Compartmentalization of inflammatory cell phenotypes in normal gingiva and peri-implant keratinized mucosa. $\mathrm{J}$ Clin Periodontol. 1995;22 (10):735-42.

17. Zitzmann NU, Berglundh T, Marinello CP, Lindhe J. Experimental peri-implant mucositis in man. J Clin Periodontol. 2001;28 (6):517-23.

18. Berglundh T, Liljenberg B, Tarkowski A, Lindhe J. Local and systemic TCR V gene expression in advanced periodontal disease. J Clin Periodontol. 1998;25 (2):125-33.

19. Taubman MA, Stoufi ED, Ebersole JL, Smith DJ. Phenotypic studies of cells from periodontal disease tissues. J Periodontal Res. 1984;19 (6):587-90.

20. Salcetti JM, Moriarty JD, Cooper LF, Smith FW, Collins JG, Socransky SS, et al. The clinical, microbial, and host response characteristics of the failing implant. Int J Oral Maxillofac Implants. 1997;12 (1):32-42.

21. Booth V, Young S, Cruchley A, Taichman NS, Paleolog E. Vascular endothelial growth factor in human periodontal disease. J Periodontal Res. 1998;33 (8):491-9.

22. Johnson RB, Serio FG, Dai X. Vascular endothelial growth factors and progression of periodontal diseases. $\mathrm{J}$ Periodontol. 1999;70 (8):848-52.

23. Marchetti C, Farina A, Cornaglia AI. Microscopic, immunocytochemical, and ultrastructural properties of peri-implant mucosa in humans. J Periodontol. 2002;73 (5):555-63.

24. Cornelini R, Artese L, Rubini C, Fioroni M, Ferrero G, Santinelli A, et al. Vascular endothelial growth factor and microvessel density around healthy and failing dental implants. Int J Oral Maxillofac Implants. 2001;16 (3):389-93.

25. Carcuac O, Berglundh T. Composition of human periimplantitis and periodontitis lesions. J Dent Res. 2014;93 (11):1083-8.

26. Christo SN, Diener KR, Bachhuka A, Vasilev K, Hayball JDJ. Innate immunity and biomaterials at the nexus: friends or foes. BioMed research international. 2015;2015:342304.

27. Curtis DA, Kao R, Plesh O, Finzen F, Franz LJJop. Crevicular fluid analysis around two failing dental implants: a clinical report. Journal of prosthodontics. 1997; 6 (3):210-4. 